\title{
Estratégias para Utilizar o Programa Prometeus na Alteração das Concepções em Mecânica*
}

\author{
Shirley Takeco Gobara ${ }^{1}$, Paulo Ricardo da Silva Rosa ${ }^{2}$, Umbelina Giacometti Piubéli ${ }^{3}$, \\ e Aline Kassab Bonfim ${ }^{4}$ \\ ${ }^{1}$ [gobara@dfi.ufms.br], ${ }^{2}$ rosa@dfi.ufms.br], ${ }^{3}$ [umbelina@dfi.ufms.br], ${ }^{4}$ [larine@enersulnet.br] \\ Universidade Federal de Mato Grosso do Sul, Departamento de Física \\ 79070-900 Campo Grande, MS, Brasil
}

Recebido em 9 de abril, 2002. Aceito em 12 de junho, 2002.

\begin{abstract}
Este artigo descreve experimentos em que foram utilizadas simulações como ferramentas para alterar as concepções espontâneas apresentadas por estudantes, de modo a explorar as possibilidades apontadas pela estratégia de conflito cognitivo (Posner et al., 1982). Os experimentos foram concebidos para tentar modificar as concepções espontâneas apresentadas em Mecânica por estudantes de nível universitário básico no desenvolvimento do conteúdo 'Leis de Newton'. Nossa abordagem ao problema baseou-se no uso de um programa de simulação chamado Prometeus, especialmente desenvolvido para esse objetivo. Realizamos três experimentos para verificar a eficácia do programa e propor a melhor estratégia de ensino a ser adotada ao utilizá-lo. Inicialmente, o programa foi testado independentemente da seqüência formal de ensino desenvolvida pelo professor. Embora a abordagem utilizada tenha se revelado útil para levar os estudantes a questionar suas crenças pessoais, a estratégia usada no primeiro experimento, baseada no uso do programa de forma isolada, não foi suficiente para promover mudanças significativas nas idéias prévias dos estudantes. No segundo experimento, o programa foi inserido no plano de ensino da disciplina como um recurso instrucional, sendo introduzido após a formalização do conteúdo 'Leis de Newton'. Como os resultados obtidos não foram satisfatórios, realizamos um terceiro experimento, com algumas modificações em relação ao anterior. Os resultados deste sugerem que a nova estratégia, somada à motivação do grupo experimental, influenciou de forma significativa a modificação das concepções dos estudantes desse grupo.
\end{abstract}

This paper describes three experiments in which computer simulations were employed as tools to modify spontaneous conceptions held by students, thus exploring the possibilities pointed out by the cognitive conflict strategy (Posner et al., 1982). The experiments were designed to try to change spontaneous conceptions found in Mechanic among students in their early years of college, during the study of the laws of Newton. Our approach was based on the use of Prometeus, a new simulation software specially designed for this purpose. Three experiments were performed to verify the suitability of the software and to identify the best teaching strategy to accompany its use. In the first of them, the program was employed alone, without connection with the teaching sequence adopted by the teacher. Although useful for leading students to question their personal beliefs, this strategy was not enough to bring about significant changes in the ideas they already held. In the second experiment, the program was employed as an instructional resource integrated into the formal teaching, but it was introduced after the classes dealing with the laws of Newton had been offered. Because the results were still not satisfactory, a third experiment was carried out, with some modifications. Its results suggest that the use of Prometeus within the new strategy, in conjunction with the motivation felt by this third group, significantly favored the overcoming of misconceptions previously held by these students.

\section{Introdução}

Um dos assuntos freqüentemente discutidos pelos pesquisadores do ensino de Ciências está relacionado com as concepções espontâneas que os estudantes apresentam, independentemente de sua escolarização. Essas concepções são esquemas explicativos construídos por meio da interação do indivíduo com o mundo físico

\footnotetext{
${ }^{*}$ Apoio: parcialmente financiado pelo CNPq e UFMS
} 
e revelam a maneira como cada indivíduo interpreta os fenômenos de seu cotidiano. Algumas dessas concepções referem-se a conceitos de Física, muitas vezes antagônicas aos modelos aceitos e utilizados no meio científico.

Pesquisas empreendidas na década de 70 buscaram levantar as diferentes concepções apresentadas pelos estudantes em relações a diversos conceitos de Física. Entre os primeiros desses trabalhos encontra-se o de Viennot (1979), realizado com estudantes franceses, que evidenciou quais eram as concepções mais freqüentes em Mecânica - mais especificamente com relação ao conceito de força e às leis de Newton —, sendo por isso de grande interesse para a pesquisa que desenvolvemos. Trabalhos posteriores dedicaram-se a identificar concepções em outras áreas da Física, como Termodinâmica, Eletricidade e Óptica.

$\mathrm{Na}$ década de 80 , as pesquisas apresentaram modelos que, inicialmente, propunham alterar as concepções apresentadas pelos alunos ou mesmo substituí-las por concepções científicas. As pesquisas também revelaram que uma das principais características das concepções espontâneas é sua forte resistência a modificações. Mesmo professores de Física podem apresentar algum tipo de concepção espontânea em algum campo da Física. Outro problema relacionado com tais concepções é que o ensino formal oferecido nas escolas nem sempre é suficiente para que o modelo científico se incorpore à estrutura cognitiva dos estudantes. Muitos deles, mesmo após terem cursado a disciplina Física, continuam se valendo de seus modelos espontâneos para explicar fenômenos físicos.

Entretanto, não existe consenso, na comunidade dos pesquisadores em ensino de Física, sobre a melhor maneira de levar um estudante a modificar suas concepções espontâneas, e nem mesmo se isso constitui um objetivo válido. Dentre as proposições que sugerem a modificação das concepções espontâneas, aquela expressa por Posner et al. (1982) aponta para a possibilidade de mudança conceitual quando os estudantes são colocados frente a situações em que as capacidades preditivas de suas concepções espontâneas falham. Essa idéia é, no entanto, difícil de ser colocada em prática. Por um lado, uma vez que as concepções espontâneas são construídas em contato direto com o mundo real, torna-se muito difícil encontrar situações do cotidiano que possam estar em contradição com as previsões advindas das idéias prévias dos estudantes. Por outro lado, não é possível, por exemplo, criar em laboratório situações em que inexistam forças resistivas, de modo a obter movimentos sem nenhum atrito. Essa, no entanto, seria uma demonstração decisiva para convencer estudantes iniciantes de que não há necessidade de aplicar forças para que um movimento se mantenha.

O uso de computadores em Educação abre novas perspectivas e desafios para as pesquisas nessa área, em particular em ensino de Física. No final do século $\mathrm{XX}$, a introdução dos computadores pessoais promoveu o desenvolvimento de grande número de aplicativos e resultou em uma maior facilidade de manuseio e na possibilidade de desenvolver aplicações menos custosas com objetivos educacionais. Como conseqüência, inúmeros artigos abordando formas de introduzir e utilizar o computador nos meios educacionais (formais e informais) têm surgido nas últimas décadas. As diversas formas de utilização de programas educacionais apresentadas na literatura podem ser agrupadas em seis categorias: $A d-$ ministração, Simulação, Instrução Assistida por Computador, Controle de Experimentos, Análise de Dados e Outras Aplicações (Rosa, 1995). Um programa usado com objetivos educacionais pode ser classificado (e geralmente esse é o caso) em duas ou mais dessas categorias.

Neste trabalho, nosso interesse recai sobre a categoria Simulação, a qual pode ser dividida em duas subcategorias: Simulação Passiva e Simulação Dinâmica. Por Simulação Dinâmica, entendemos aquela que exige dos estudantes a criação de modelos ou, ao menos, a definição dos valores dos parâmetros de uma dada situação. Por outro lado, entendemos por Simulação Passiva aquela que não envolve qualquer processo de decisão por parte do estudante. O programa que desenvolvemos para esta pesquisa, chamado Prometeus (Rosa et al., 1997), pertence à primeira subcategoria. Trata-se de um programa que exige que os estudantes façam escolhas entre diferentes modelos propostos.

Nosso objetivo, ao conceber esse programa, foi criar condições similares àquelas que provocam o aparecimento das concepções espontâneas. Para tanto, fizemos uso de um ambiente de simulação em microcomputador. Com esse procedimento, tivemos em mente induzir os estudantes a levantar questões para si mesmos sobre suas idéias anteriores e levá-los a comparar essas idéias com os resultados obtidos a partir de simulações feitas pelo programa.

Dentre as muitas questões que podem ser levantadas sobre esse assunto, aquela que permeou o presente trabalho foi a seguinte: é possível alterar as concepções espontâneas apresentadas pelos estudantes em Mecânica ao fazerem uso de um programa capaz de criar em microcomputador um mundo virtual no qual essas concepções sejam verdadeiras?

Realizamos três experimentos para verificar a eficácia do programa Prometeus e propor a melhor estratégia de ensino a ser adotada ao utilizá-lo. Na seção 
2 é apresentada uma discussão sucinta do programa; na seção 3, uma síntese dos dois experimentos iniciais e seus resultados mais relevantes; na seção 4 , um relato do último experimento. As seções 5 e 6 trazem, respectivamente, as principais conclusões e a bibliografia.

\section{O programa Prometeus ${ }^{1}$}

Prometeus é um programa escrito na linguagem $\mathrm{C}++$. É projetado para rodar sob os ambientes DOS, Windows e OS/2, sem necessidade de recompilação, e sob os sistemas operacionais System 7 e 8 e Unix com poucas modificações e recompilação, uma vez que seu código-fonte não utiliza recursos do sistema de maneira intensiva.

O programa compõe-se de dois módulos: um módulo de gerência (a ser usado por pesquisadores ou professores) e um de usuário (a ser utilizado pelos estudantes).

O primeiro módulo executa as tarefas de gerência do sistema pelo professor, registrando todas as interações dos alunos com o programa. Esse módulo é composto de dois submódulos: Inclusão/Exclusão e Relatórios. O de Inclusão/Exclusão permite ao gerente do sistema cadastrar usuários novos e excluir antigos. O submódulo Relatórios permite ao gerente obter informações, tanto em nível individual como em nível de grupo, sobre o desempenho dos estudantes enquanto utilizam o programa: escolhas feitas, tempo utilizado em cada seção, valores médios de tempo utilizado por seção etc.

O segundo módulo, responsável pela apresentação das simulações, traz a interface gráfica na qual ocorre a interação entre o estudante e o programa. Para usar o programa, é necessário o uso de uma senha, a qual é fornecida automaticamente pelo programa quando o estudante é cadastrado.

O programa contém quatro tipos de problemas relacionados com situações do cotidiano: Vôlei, Saque, Circular e Planetas. A idéia básica é reproduzir situações do mundo real e dar ao estudante a oportunidade de comparar os resultados das simulações com sua experiência de vida.

A categoria Vôlei apresenta várias situações em que um garoto faz um saque sobre uma rede em uma quadra de vôlei. Na segunda categoria, Saque, o mesmo garoto bate na bola de modo a arremessá-la para cima e pegála quando ela retorna. Na terceira categoria de problemas, Circular, o garoto gira em torno de si, em círculos, uma bola ligada por uma corda fina. Por fim, a categoria Planetas mostra um planeta que gira em torno do Sol. A órbita e a velocidade do planeta obedecem às leis de Kepler.
Para cada categoria de simulação existem três ou quatro subsituações, entre as quais há pequenas variações (por exemplo, o ponto em que a imagem é congelada). A situação a ser explorada é de escolha do estudante. Para cada uma, ele dispõe de cinco opções, cada uma apresentando um diagrama de forças que mostra uma ou mais forças que são as possíveis causas do movimento observado.Uma das opções oferecidas é aquela aceita como correta pela comunidade científica, e as demais correspondem às concepções espontâneas comumente detectadas em pesquisas sobre o assunto.

O modus operandi do programa é o seguinte: o estudante escolhe uma dada situação e o programa simula tal escolha de acordo com as leis da Física corretas para aquele caso. Após alguns segundos, o programa pára e congela a imagem na tela, perguntando ao estudante qual dentre as opções apresentadas é a correta. Após o estudante ter escolhido uma delas, o programa prossegue a simulação, mas desta vez seguindo a lei proposta pelo estudante. A nova trajetória dos vários objetos é calculada através da solução numérica da segunda lei de Newton, usando como força resultante aquela proposta pelo estudante. Após alguns segundos, o programa pergunta ao estudante se deseja continuar utilizando aquela simulação ou trabalhar em outra situação. As simulações podem ser repetidas quantas vezes o usuário desejar.

O programa Prometeus foi concebido de modo a apresentar duas características principais:

As simulações sempre seguem as regras propostas pelo usuário.

O programa não revela a resposta correta. Mesmo quando a resposta do estudante é a correta, o programa não lhe informa se houve acerto ou não.

A estratégia geral adotada é, então, a de levar o estudante a vivenciar um conflito entre suas crenças e os resultados da simulação que escolheu desenvolver. Tal conflito cognitivo se manifestará sempre que se vir frente a um resultado inesperado, que difira daquele previsto a partir de suas concepções espontâneas. Apenas a escolha da simulação correta evitará esse confronto conflituoso.

Um caso típico de trabalho consiste em simular uma dada situação habitualmente encontrada em problemas apresentados em livros didáticos de Física. A Fig. 1 mostra um exemplo, da categoria Planetas, em que um planeta (1), a Terra por exemplo, está representado pela esfera menor e o Sol (2) pela esfera maior. A simulação começa com o planeta girando em torno do Sol, seguindo as leis de Kepler.

\footnotetext{
${ }^{1} \mathrm{O}$ programa Prometeus foi premiado em segundo lugar no Concurso Nacional de Software para Instituições de Ensino Superior, patrocinado pelo MEC, em 1997.
} 
Após o planeta haver executado algumas voltas em torno do Sol, a simulação é interrompida e a imagem é congelada, como mostra a Fig. 2, e o estudante é questionado sobre as forças que governam o fenômeno. Isso lhe permite escolher entre cinco opções, exibidas na lateral direita da imagem.

Das opções disponíveis, uma é correta e as demais são aquelas detectadas por pesquisas sobre concepções espontâneas (Viennot, 1979; Driver e Eckison, 1983; Ogborn, 1985; Gilbert e Zylberztajn, 1985; Peduzzi e Peduzzi, 1985 a,b; Silveira et al., 1986; Guimarães, 1987). Com esse procedimento, visou-se nessa etapa apresentar aos estudantes os caminhos epistemológicos que eles naturalmente trilhariam ao seguir suas concepções espontâneas. A escolha de uma das opções apresentadas leva o programa a simular o movimento do planeta de acordo com a lei de força proposta pelo estudante. Feitas algumas repetições, o programa propõe duas alternativas: o estudante pode prosseguir com a mesma escolha ou começar uma nova simulação, baseada em outra das opções. Estas duas alternativas são propostas mesmo no caso de uma resposta correta.

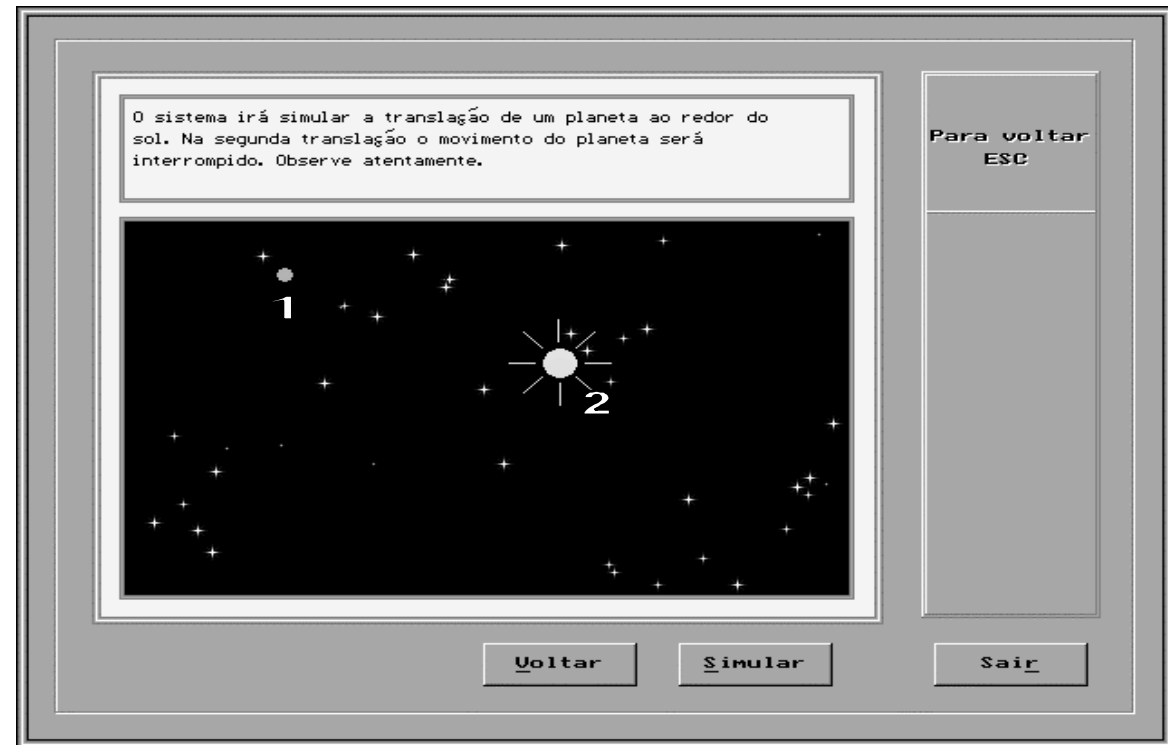

Figura 1. Simulação do movimento de um planeta em torno do Sol.

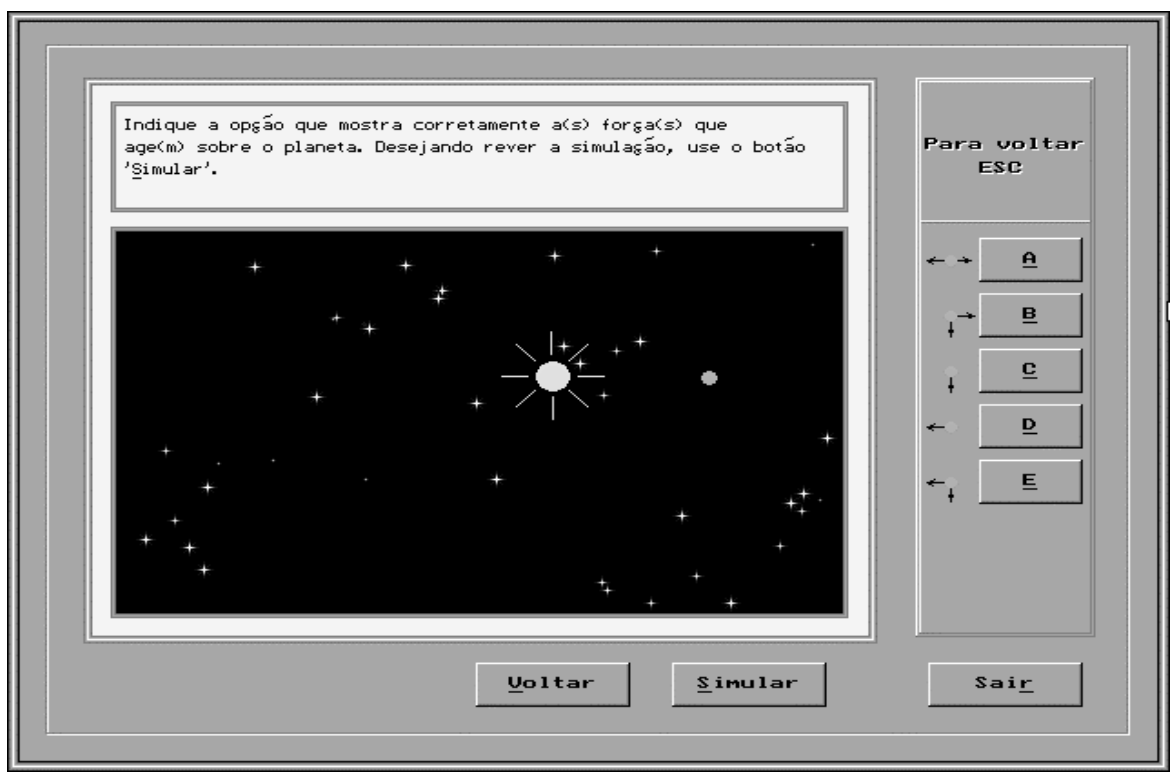

Figura 2. Opções apresentadas aos alunos em uma das simulações na situação Planetas. 


\section{Síntese dos dois experimentos iniciais}

Os três experimentos foram realizados com o objetivo de analisar como o uso do programa Prometeus influencia a alteração das concepções espontâneas de alunos em nível universitário básico. Faremos aqui uma discussão sucinta sobre os pressupostos teóricos que nortearam a pesquisa e um relato breve dos dois experimentos inicialmente realizados.

Vários trabalhos abordando concepções espontâneas são encontrados na literatura, sendo o de Viennot (1979), realizado com estudantes franceses, um dos primeiros. Resumidamente, seus principais resultados, referentes ao conceito de força e às leis de Newton, revelaram as seguintes concepções espontâneas sobre a relação entre força e velocidade:

a) Existência de uma força intrínseca ao corpo em movimento, que explica a permanência deste em movimento após ser lançado;

b) Proporcionalidade entre força e velocidade, sendo que a variação da força corresponde à variação da velocidade;

c) Indiferenciação entre força e energia cinética.

Embora as pesquisas tenham discutido exaustivamente a forte resistência dos estudantes a abandonar suas concepções espontâneas, elas também têm mostrado que o ensino formal nem sempre é suficiente para que o modelo científico seja incorporado à estrutura cognitiva do indivíduo. Muitos estudantes, mesmo após terem cursado a disciplina Física, geralmente nos primeiros anos de curso, continuam utilizando seus modelos espontâneos para explicar fenômenos físicos. Isso mostra a necessidade de se desenvolverem metodologias de ensino que levem em consideração as idéias prévias dos estudantes e que promovam a substituição de conceitos espontâneos por científicos.

Uma das propostas desenvolvidas com esse objetivo é o modelo de mudança conceitual, de Posner (1982). Segundo esse autor, é necessário criar situações que não possam ser satisfatoriamente explicadas pelos modelos espontâneos, de modo a evidenciar um conflito cognitivo e, a partir das insatisfações assim provocadas, levar o estudante a construir o novo conceito. Essas insatisfações com o modelo disponível correspondem aos chamados "desequilíbrios" na teoria de Piaget (Piaget e Inhelder, 1971; Piaget, 1975; Piaget 1978), que serviu de base para o trabalho de Posner. De acordo com Piaget, um indivíduo constrói, através da experiência direta com o mundo físico, esquemas de assimilação aos quais vão se incorporando novas experiências com o passar do tempo. Quando uma nova situação não pode ser explicada por esquemas presentes na estrutura cognitiva, ocorre um desequilíbrio que pode levar a diferentes caminhos. Uma das possibilidades é ocorrer assimilação, quando uma nova idéia é "transformada" para adaptar-se à estrutura cognitiva, antes de chegar a se incorporar a ela. Pode também ocorrer acomodação, quando os esquemas se modificam e, em conseqüência, a estrutura cognitiva se altera para incorporar a nova idéia. Há, ainda, a possibilidade de refutação da nova situação pelo sujeito, que mantém inalterada sua estrutura cognitiva.

O modelo de mudança conceitual de Posner tem por objetivo levar à acomodação de novos conceitos. Para que isso ocorra, porém, o estudante deve manifestar insatisfação com relação às concepções de que dispõe. Além disso, o novo conceito deve ser inteligível, plausível, prever novos fenômenos e possibilitar o desenvolvimento de novas indagações. Caso contrário, o estudante não sentirá necessidade de mudança.

\section{III.1. Delineamento e resultados do Ex- perimento I}

No primeiro experimento (Gobara et al., 2000), o programa Prometeus foi testado independentemente da seqüência formal de ensino desenvolvida pelo professor. Com essa abordagem, visamos criar nos estudantes um conflito conceitual da maneira apontada por Posner et al. (1982): uma insatisfação com suas idéias anteriores quando estas perdem seu caráter preditivo.

De modo a investigar a eficiência da estratégia escolhida para alterar as concepções espontâneas dos estudantes, optamos por um delineamento experimental utilizando pré e pós-testes, simbolicamente representado pelo diagrama 1 (Campbell and Stanley, 1979):

$$
\begin{array}{lll}
O_{1} & & O_{2} \\
O_{3} & X & O_{4}
\end{array}
$$

Diagrama 1- Delineamento experimental.

Neste tipo de diagrama, o tempo flui da esquerda para a direita, e cada linha mostra a seqüência de observações feitas sobre cada grupo. $O_{1}$ representa a primeira observação sobre o primeiro grupo. Essa observação é seguida por outra, simbolizada por $\mathrm{O}_{2}$. O símbolo $X$ indica que aplicamos um tratamento ao segundo grupo, e que ele se deu entre a primeira e a segunda observações desse grupo (aqui simbolizadas por $\mathrm{O}_{3}$ e $\mathrm{O}_{4}$ ). É importante salientar que a observação rotulada como $O_{1}$ para o primeiro grupo é feita concomitantemente com a observação rotulada como $O_{3}$ para o segundo grupo.

Em nosso Experimento I, o grupo de controle e o experimental, ambos com 15 estudantes, provieram de uma turma à qual se ministrava a disciplina Física Teórica no curso de Engenharia da Universidade Federal de Mato Grosso do Sul. Essa disciplina cobre conteúdos de Mecânica e Termodinâmica. Como em todo curso regular de uma universidade, a turma da qual os dois grupos foram retirados não é formada 
aleatoriamente a partir da população total. Logo, os grupos de controle e experimental, embora formados por escolha aleatória dentro da turma, onde a atribuição de um aluno da turma ao grupo de controle ou ao grupo experimental foi feita por sorteio, não satisfazem o critério de escolha aleatória dentro da população; daí a necessidade de um delineamento de tipo experimental com pré-teste (Campbell e Stanley, 1979).

O programa não foi usado no ambiente de sala de aula como ferramenta instrucional por parte do professor. Os estudantes do grupo experimental, por sua vez, receberam as seguintes orientações sobre o uso do programa:

a) Seu comparecimento ao laboratório de computação seria opcional, e eles o freqüentariam em horários diferentes dos horários de aula.

b) Eles teriam livre acesso ao laboratório de computação.

Tornamos opcional o uso do programa pelo grupo experimental por pretendermos verificar uma segunda questão: se o programa, por si só, seria capaz de estimular os estudantes a utilizá-lo quando não houvesse obrigatoriedade de fazê-lo.

O grupo de controle não teve nenhuma interação com o programa durante o experimento. Nenhum dos grupos tivera contato anterior com o programa. Ambos os grupos tiveram o mesmo professor.

O pré-teste compôs-se de três verificações independentes.

1. Um teste escrito sobre concepções espontâneas;

2. A análise dos escores no exame de Física do vestibular;

3. Um Teste de Associação Numérica de Conceitos.

O pós-teste, por sua vez, também se compôs de três verificações independentes:

1. Um teste escrito sobre concepções espontâneas, mas diferente do pré-teste;

2. A análise de entrevistas realizadas enquanto os alunos utilizavam o programa;

3. Um Teste de Associação Numérica de Conceitos, também diferente do pré-teste.

Os resultados obtidos com esses diferentes instrumentos, somados aos resultados das entrevistas realizadas com os estudantes do grupo experimental, mostraram que a estratégia baseada no uso do programa, mas de forma independente do trabalho em sala, não se mostrou eficaz para modificar as concepções espontâneas. As entrevistas revelaram, porém, que a confiança dos estudantes em suas idéias prévias atenuou-se após a interação com o programa. Ape- sar disso, eles não mostraram uma clara modificação dessas crenças em direção às idéias científicas. Ao escolherem a opção que simulava uma das concepções espontâneas, eles se surpreendiam e buscavam outras opções. Em nenhum momento, explicitamente, manifestaram dúvidas quanto à veracidade das situações simuladas pelo programa. Todos aceitaram a hipótese de que o programa estava correto, o que sugere que o computador gera nos estudantes confiança absoluta.

As opções escolhidas nas diferentes simulações confirmaram as concepções espontâneas desses estudantes anteriormente detectadas no pré-teste escrito. O programa, portanto, pode ser usado como ferramenta de detecção dessas concepções, em lugar de testes escritos.

Os resultados desse primeiro experimento, embora não tenham conduzido os estudantes às mudanças que esperávamos, nos levaram a supor que, se o programa fosse inserido no plano de ensino da disciplina como uma ferramenta regular, sendo respeitados os preceitos da estratégia de conflito cognitivo, seus efeitos poderiam ser mais fortes e observáveis.

\section{III.2. Delineamento e resultados do Ex- perimento II}

O segundo experimento (Bonfim, 2000) foi realizado levando em conta os objetivos e os resultados do primeiro. O programa Prometeus, neste caso, foi utilizado como material instrucional durante o desenvolvimento do conteúdo 'Leis de Newton' para os alunos da disciplina Física Geral e Experimental do curso de Matemática, Licenciatura Plena, no ano 2000, na mesma instituição. Esse grupo era inicialmente constituído por 18 estudantes. No decorrer das atividades, alguns deles desistiram da disciplina e até mesmo do curso, o que é comum em cursos da área de Exatas. Apenas 11 estudantes concluíram a disciplina.

A impossibilidade de dividir o grupo escolhido em dois subgrupos fez com que executássemos um delineamento pré-experimental, apenas com pré e pós-testes, representado pelo diagrama 2 (Campbell e Stanley, 1979), ou seja, um delineamento que incluiu apenas o grupo experimental. .

\section{$\begin{array}{lll}O_{1} & \mathrm{X} & \mathrm{O}_{2}\end{array}$}

Diagrama 2- Delineamento pré-experimental

Adotou-se como metodologia de pesquisa a esquematizada no diagrama 3. 


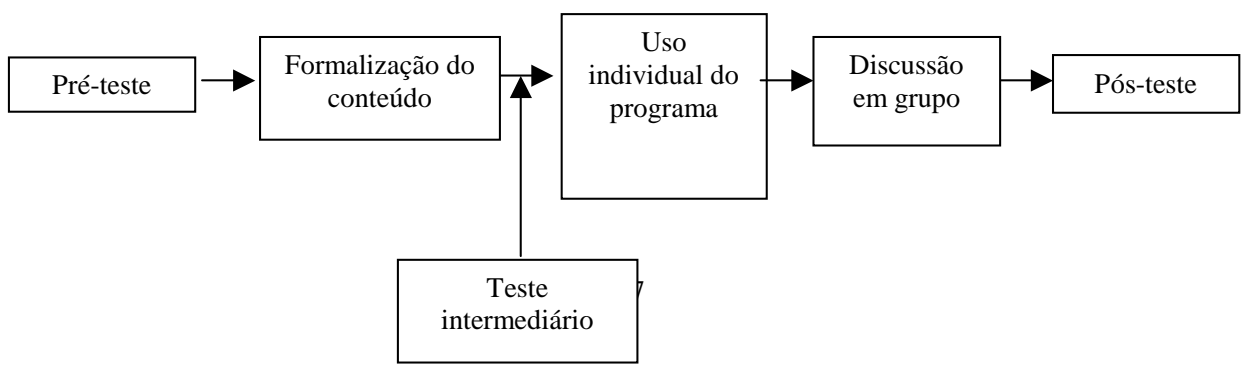

Diagrama 3 - Metodologia do Experimento II

A primeira atividade realizada no desenvolvimento desta pesquisa foi a aplicação de um pré-teste (7/4/2000) para identificar as concepções do grupo. Em seguida, o conteúdo 'Leis de Newton' foi introduzido e formalizado durante as aulas. Após essa formalização, os estudantes fizeram o teste intermediário (30/5/2000), cujo objetivo era verificar se alguma mudança havia ocorrido apenas com o estudo formal das leis de Newton.

$\mathrm{Na}$ aula seguinte ao teste intermediário, ocorreu a primeira interação, individual e obrigatória, com o programa Prometeus. Nessa oportunidade, foi sugerido aos estudantes que voltassem a utilizar o programa em novas interações. Após a primeira interação, houve uma discussão em sala de aula, no mesmo dia, sobre as situações proporcionadas pelo programa, para verificar se este havia levado os estudantes a perceberem insatisfações com relação a suas concepções espontâneas. Após um intervalo de um mês e alguns dias, foi aplicado o pós-teste $(11 / 7 / 2000)$.

A análise dos testes da amostra considerada (8 alunos que participaram dos três testes) consistiu em comparar qualitativamente as respostas apresentadas no pré-teste (do qual participaram 16 alunos que não haviam ainda interagido com o programa), as respostas do teste intermediário (11 alunos que haviam participado das aulas sobre o conteúdo 'Leis de Newton') e as respostas do pós-teste (12 alunos que haviam interagido com o programa). Também fez parte da análise uma entrevista realizada com o professor da disciplina.

Analisando o pré-teste aplicado aos estudantes, verificamos que as concepções mais freqüentes para o grupo de 8 alunos considerado foram as mesmas sugeridas pelo trabalho pioneiro de Viennot (1979). Todos os estudantes se revelaram possuidores de concepções espontâneas exaustivamente repertoriadas pela literatura já citada.

Nas subseções seguintes, serão apresentados os resultados das análises de cada teste, relatando-se as possíveis mudanças nos modelos espontâneos dos estudantes, bem como sua permanência e resistência à mudança desses modelos.

\section{III.2.1 Resultados do pré-teste e do teste inter- mediário}

A análise do pré-teste dos estudantes que participaram do Experimento II nos confirmou, como já era esperado, que as concepções apresentadas por esse grupo eram as mesmas apontadas pelo trabalho de Viennot.

No teste intermediário, não foram constatadas alterações significativas nas concepções espontâneas desses estudantes. Eles continuaram apresentando a idéia de que a força é aplicada na direção do movimento. É o que mostram suas respostas à questão 1 desse teste, a qual tratava de uma pedra lançada horizontalmente. Todas as respostas envolveram duas forças: uma horizontal, que faz o corpo ir para a frente, e outra vertical, que faz o corpo cair. A análise do teste intermediário nos confirmou que o ensino formal oferecido após o préteste não foi suficiente para levar esses estudantes a abandonar seus modelos espontâneos, servindo também para nos certificarmos de que não haviam ocorrido mudanças antes de passarmos ao tratamento experimental que se seguiria: a utilização do programa Prometeus.

\section{III.2.2 Análise da interação dos alunos com o programa Prometeus}

Após a primeira interação com o programa, os estudantes tiveram acesso livre a ele - incluindo incentivo a seu uso - até o pós-teste ser aplicado. Os dados armazenados no próprio programa revelaram, porém, que as interações foram poucas, não correspondendo a nossas expectativas, o que interpretamos como um desinteresse desses estudantes pelo programa.

Após a primeira interação, ocorreu a discussão com o grupo. Nela, analisaram-se as situações do programa, as quais foram discutidas uma por uma, no quadro-negro, com os estudantes. Segundo a professora responsável pela disciplina e pela execução da metodologia adotada, durante a discussão os estudantes não mostraram estar insatisfeitos com seus modelos espontâneos. Ao longo dessa discussão, segundo a professora, os estudantes conseguiram responder algumas questões corretamente por serem muito semelhantes. 


\section{III.2.3 Análise e resultados do pós-teste}

O pós-teste foi constituído de 11 questões de múltipla escolha aplicadas após os estudantes terem interagido com o programa Prometeus e discutido sobre as situações do programa com o professor. O objetivo desse teste foi verificar a ocorrência de alterações das concepções apresentadas no pré-teste e no teste intermediário.

Nas questões 1 a 4 solicitava-se aos estudantes que assinalassem a alternativa que representava as forças que estavam agindo sobre o corpo em movimento.

A questão 1 tratava de uma bola de sinuca que, ao receber uma tacada de um jogador, movia-se sobre a mesa em direção à caçapa. Com exceção de um estudante, todos assinalaram alternativas que apresentavam uma força na direção do movimento da bola, revelando, assim, a permanência de um modelo espontâneo.

A questão 2 tratava de um bloco que era jogado de baixo para cima ao longo de um plano inclinado liso. (A figura no teste representava o corpo subindo.) Não houve acertos nessa questão. Dois estudantes, entretanto, consideraram uma força agindo na direção do plano, embora em sentido contrário ao do movimento do bloco. O restante do grupo considerou uma força na direção do plano e agindo sobre o bloco no mesmo sentido do movimento ("puxando-o para cima").

Na questão 3, que tratava de uma pedra lançada horizontalmente da janela de um edifício, e na questão 4, referente à trajetória parabólica de uma bola lançada por um jogador de golfe, ocorreu um grande número de acertos. A questão 3 do pós-teste e a questão 1 do teste intermediário eram idênticas. Ao verificarmos o desempenho dos estudantes em ambos os testes, constatamos uma melhora significativa no número de acertos, passando de zero no teste intermediário para seis no pósteste. Esse resultado nos pareceu indicar que esses estudantes, ao interagirem com o programa, teriam sido influenciados a ponto de questionar e reavaliar as respostas dessas questões, visto que o programa Prometeus oferece uma situação semelhante às questões 3 e 4 do pós-teste. Trata-se da situação em que um garoto dá um saque numa bola de vôlei, sendo a imagem congelada após a bola atravessar a rede (Figura 3 ). O programa pede então que o estudante escolha a alternativa que apresenta as forças que atuam nessa situação.

A análise das demais questões do pós-teste, entretanto, revelou a forte presença de concepções já observadas no pré-teste e no teste intermediário. Os estudantes continuavam associando aumento de força com aumento de velocidade.

No geral, verificamos que os estudantes não obtiveram bons desempenhos. A análise dos testes mostrou que nem o ensino formal nem o programa Prometeus foram, no espaço de tempo observado, potencialmente eficazes para alterar os modelos espontâneos da maioria dos estudantes do grupo considerado.

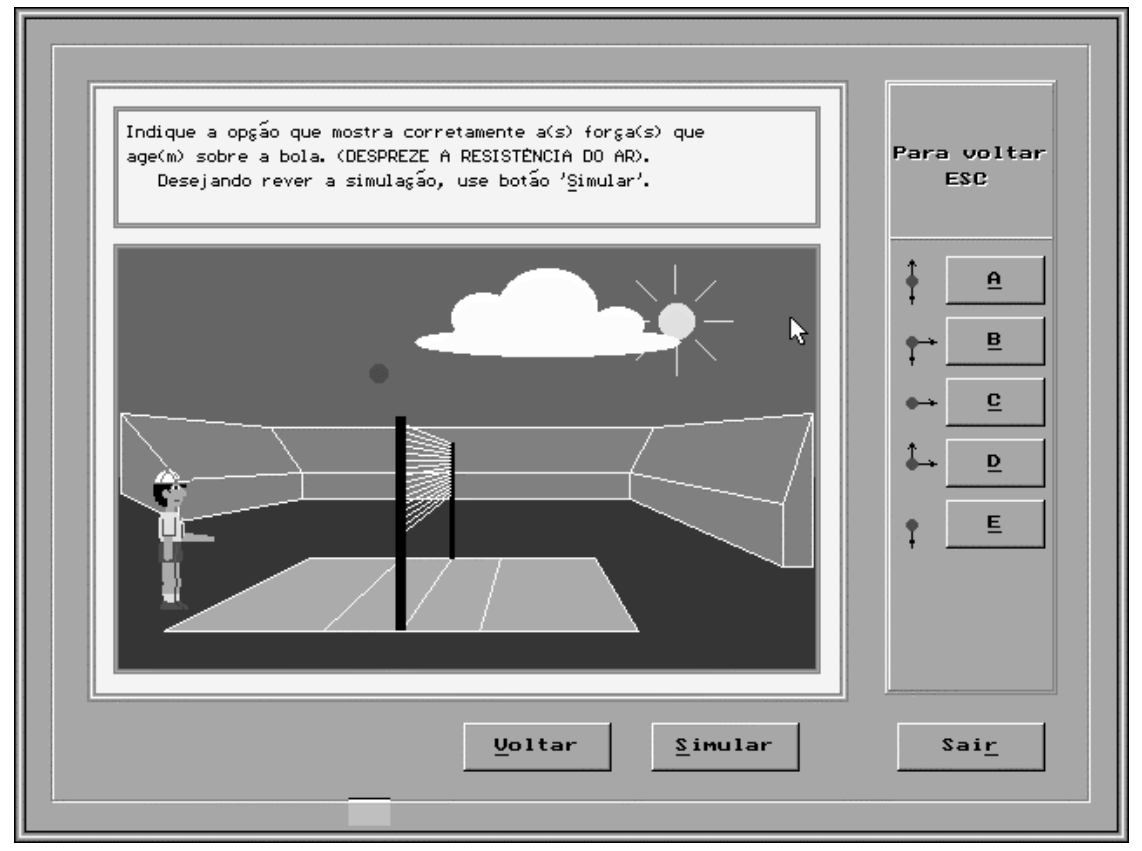

Figura 3. Tela do Prometeus em situação da categoria Vôlei. 
A esse resultado soma-se a desmotivação manifestada por esses estudantes em relação à disciplina Física Geral e Experimental, já que se tratava de alunos de um curso de Matemática. Entretanto, de acordo com a professora responsável pela disciplina, o comentário que se ouviu dos estudantes foi o seguinte: "O programa serviu para nos mostrar que não sabemos as leis de Newton, como pensávamos saber." Essa afirmação pode ser analisada sob dois aspectos: um que confirma o resultado observado no Experimento I, em relação à confiança absoluta no programa, e outro que está relacionado ao papel auto-avaliativo do programa, evidenciado nos comentários espontâneos dos estudantes.

Esses resultados, embora não tenham conduzido ao objetivo maior, que era o de provocar uma alteração das concepções desses estudantes, revelaram algumas mudanças em seu comportamento em comparação com o primeiro experimento, guardadas as limitações comparativas entre os experimentos. Restava ainda investigar outras hipóteses que não tinham sido esgotadas nesses dois experimentos: a intensificação das discussões, entre estudantes e professor, das situações propostas pelo Prometeus e a motivação pelo assunto.

\section{Metodologia e desenvolvi- mento do Experimento III}

Como continuidade a nosso trabalho, para verificar se o programa Prometeus poderia contribuir na alteração de concepções espontâneas dos estudantes, implementamos um novo experimento com uma metodolo- gia semelhante à do Experimento II, embora para uma amostra experimental diferente, visto que, neste caso, estávamos interessados em verificar o aspecto motivacional do conteúdo do programa (Bonfim e Gobara, 2001). O grupo escolhido foi uma turma de alunos do curso de Bacharelado em Física, 2001, constituída por calouros e alunos que haviam sido reprovados na disciplina Mecânica e Termodinâmica F.

O delineamento utilizado para o desenvolvimento do Experimento III foi o mesmo utilizado no Experimento II, ou seja, apenas com um grupo experimental. A diferença entre as metodologias é que, neste terceiro e último experimento, os estudantes interagiram uma única vez com o programa. Não foi aplicado teste intermediário, mas intensificou-se a discussão das situações apresentadas no programa. Essa escolha derivou dos resultados das pesquisas anteriores (Gobara et al., 2000; Bonfim, 2000). O diagrama 4 apresenta a metodologia da pesquisa desenvolvida neste experimento final.

Primeiramente foi aplicado o pré-teste (10/4/2001) e, em seguida, foi ministrado todo o conteúdo 'Leis de Newton'. Após a formalização do conteúdo, os estudantes interagiram com o programa Prometeus, seguindo-se então a discussão em grupo das situações apresentadas pelo programa. A última atividade da seqüência foi a aplicação do pós-teste (1/6/2001), sendo que no período entre a interação com o programa e o pós-teste os estudantes realizaram a prova normal do curso sobre o conteúdo de Dinâmica.

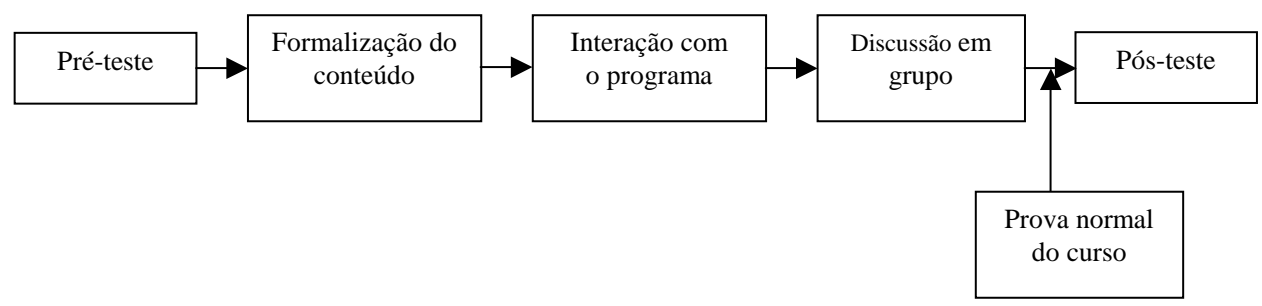

Diagrama 4 - Metodologia da pesquisa do experimento III.

Do grupo inicial, 26 estudantes realizaram o préteste, 21 realizaram o pós-teste e 21 interagiram com o programa. Como nosso critério foi incluir na amostra final apenas os estudantes que houvessem participado das três atividades, pudemos analisar somente os testes de 14 estudantes.

O pré-teste foi elaborado com 6 questões de múltipla escolha, as quais já haviam sido utilizadas no teste intermediário para o grupo de estudantes de Matemática. Além de escolherem uma alternativa, os estudantes deveriam, desta vez, justificá-la.

As mesmas concepções observadas no pré-teste do grupo de Matemática foram identificadas para o grupo de Física, como mostram estes exemplos:
Justificativa do estudante SA para a questão em que uma pedra era lançada horizontalmente: "Existem duas forças agindo sobre a pedra, uma horizontal, que fez com que a pedra fosse lançada para fora da janela, $e$ outra vertical para baixo, atraindo para o solo". (Concepção A.)

Justificativa do estudante DE para a questão em que um garoto empurrava uma caixa: "(...) pois a força aplicada é um pouco maior que a força de atrito, logo a velocidade vai ser constante e também pequena". (Concepção B.)

No pós-teste, que conteve as questões já utilizadas com o grupo de Matemática, verificamos diversas mudanças. O estudante DA, na quinta questão do pré- 
teste, sobre o garoto empurrando a caixa, justificou desse modo sua escolha de uma alternativa baseada em concepção espontânea: "Se a força diminuir com a ação de uma força externa contrária a ela, sua velocidade também diminuiria". Já no pós-teste, para uma questão sobre um elevador, que explora uma situação física semelhante à da questão sobre a caixa, o estudante assim justificou sua escolha da alternativa correta: "Mesmo que a força aplicada pelo motor diminua, continua sendo maior que o peso, então existe uma aceleração e a velocidade aumenta".

A análise do pós-teste mostrou também que o maior número de erros ocorreu nas questões 5 e 6 , referentes ao motor exercendo força sobre o elevador e que abordam a concepção de força proporcional à velocidade.

Na Tabela 1, compara-se o desempenho dos estudantes em ambos os testes: ( $\mathrm{S}=$ sim, presença de concepções, e $\mathrm{N}=$ não, ausência de concepções). Concluímos, com a análise dos testes, que todos os estudantes a que se atribuiu "S" nessa tabela continuavam apresentando a concepção B. Os estudantes AL, DE, RO e VI foram os únicos que continuaram apresentando também a concepção A.

\begin{tabular}{|c|c|c|c|c|}
\hline \multirow{2}{*}{ Aluno } & \multicolumn{2}{|c|}{ Acertos } & \multicolumn{2}{c|}{ Concepções } \\
\cline { 2 - 5 } & Pré-teste & Pós-teste & Pré-teste & Pós-teste \\
\hline AF & 6 & 7 & N & N \\
\hline AL & 0 & 3 & S & S \\
\hline AP & 1 & 7 & S & N \\
\hline CL & 2 & 7 & S & N \\
\hline DA & 1 & 7 & S & S \\
\hline DE & 0 & 0 & S & S \\
\hline GE & 1 & 6 & S & S \\
\hline HA & 1 & 5 & S & N \\
\hline KE & 1 & 3 & S & S \\
\hline RA & 0 & 7 & S & S \\
\hline RO & 1 & 3 & S & S \\
\hline SA & 0 & 7 & S & S \\
\hline VI & 0 & 2 & & \\
\hline YA & 0 & 4 & & S \\
\hline
\end{tabular}

Tabela 1. Tabela comparativa de desempenho dos estudantes.

O que a Tabela 1 mostra é que a maioria dos estudantes evoluiu do pré-teste para o pós-teste, o que é revelado pelos números de acertos nas questões. As exceções, como pode ser visto, foram os estudantes DE, que não apresentou nenhuma evolução, e AF, que não apresentou concepções espontâneas em nenhum dos testes.

Na discussão com esse grupo de Física, as situações do programa foram apresentadas utilizando-se um datashow. De acordo com a professora ${ }^{22}$, o comportamento dos estudantes de Física foi muito diferente daquele dos de Matemática.

Segundo a professora, os estudantes mostraram-se animados já na atividade de interação com o Prometeus, inclusive fazendo disputas para ver quem conseguiria acertar as questões com o menor número de tentativas. Na fase de discussão em sala de aula eles também se mostraram mais participativos, fazendo perguntas e também debatendo uns com os outros.

Essa diferença de comportamento em relação à turma de Matemática pode ser explicada principalmente pelo interesse dos estudantes de Física pela disciplina e pelo conteúdo 'Leis de Newton'. Os integrantes desse grupo, segundo a professora, tiveram maior inte- resse na atividade de interação com o programa, sendo que alguns deles manifestaram vontade de mostrá-lo para colegas que não cursavam Física, a fim de "testálos". Ela revelou ainda que, comparando-se as turmas experimentais de Matemática e de Física, a primeira se mostrou mais apática e passiva durante a execução do programa e principalmente na discussão em grupo.

Em conjunto, os resultados obtidos da análise dos testes sugerem que a nova metodologia adotada, somada à motivação dos estudantes de Física, contribuiu para o bom desempenho obtido no pós-teste, em comparação com as concepções apresentadas no pré-teste.

\section{Conclusões}

Sabe-se que, a partir da interação com o mundo físico, as pessoas, e particularmente os estudantes, constroem os chamados modelos espontâneos, e os põem então em uso para explicar os fenômenos observados no dia-a-dia. Tais modelos, como nossa pesquisa também confirmou, dificilmente se alteram através da simples exposição dos estudantes a conteúdos científicos.

As principais concepções espontâneas em Mecânica apontadas na literatura foram identificadas nos pré-

${ }^{22}$ A professora responsável pela disciplina Mecânica e Termodinâmica F para o curso de Bacharelado em Física, 2001, foi a mesma do grupo de Matemática. 
testes dos três experimentos. A interação dos estudantes com o programa revelou-se potencialmente útil para detectar essas concepções.

Cabe aqui reforçarmos que o objetivo principal de nossa pesquisa não foi testar a qualidade do programa Prometeus, mas identificar suas possíveis influências na alteração de concepções espontâneas quando inserido no desenvolvimento do conteúdo de uma disciplina. Nossos resultados mostraram que uma estratégia baseada apenas na interação isolada do estudante com o programa não é a mais adequada, como revelou a análise dos testes do Experimento I.

No segundo experimento, a primeira interação dos estudantes com o programa Prometeus ocorreu após o teste intermediário, quando já haviam estudado todo o conteúdo 'Leis de Newton'. Foi-lhes sugerido que, além da primeira interação obrigatória, retornassem ao laboratório para utilizar o programa outras vezes. Nossa expectativa, ao inserirmos o programa no desenvolvimento do conteúdo da maneira como o fizemos, era que os estudantes viessem a utilizá-lo várias vezes, levantando questões que, pouco a pouco, pudessem levá-los a substituir seus modelos espontâneos pelo científico. Como visto na análise da interação dos alunos com o programa, a falta de interesse e atenção nessa atividade foi um fator que contribuiu desfavoravelmente para os resultados obtidos ao final dessa etapa do trabalho.

Outro fator que contribuiu para tais resultados insatisfatórios foi a falta de motivação dos estudantes quanto à disciplina Física Geral e Experimental, o que talvez se deva ao fato de serem alunos do curso de Matemática. Em decorrência desses resultados, desenvolvemos uma nova estratégia que apresentava semelhanças à que fora utilizada com esses estudantes. Os resultados obtidos para essa nova amostra foram satisfatórios, mesmo tendo ocorrido uma única interação com o programa. Esse resultado pode ser atribuído, neste caso, ao interesse dos estudantes pelo programa, o que os motivou a se dedicarem às atividades e, principalmente, a participarem energicamente da discussão das situações. Essa discussão foi considerada por esse grupo como uma das atividades mais importantes, e mostrou-se fundamental para que o grupo pudesse esgotar as insatisfações provocadas pelas situações apresentadas pelo programa. Neste caso, uma única interação, mas com possibilidade de várias tentativas, foi suficiente para o bom desempenho verificado no pósteste.

As estratégias que desenvolvemos utilizando o programa Prometeus, com o objetivo de levar os estudantes a alterar seus modelos espontâneos, substituindo-os por modelos científicos, podem servir de referência para professores que queiram trabalhar as concepções espontâneas de seus estudantes. As situações propostas por esse programa não se esgotam apenas nas simulações realizadas pelos estudantes. Como os experimentos mostraram, é preciso utilizá-lo em conjunto com es- tratégias adequadas, as quais devem ser buscadas em função das características de cada grupo, de modo a permitir que as concepções espontâneas, além de terem sua existência reconhecida, sejam adequadamente trabalhadas, mesmo que se mostrem muito resistentes a mudanças.

Cópias do programa Prometeus podem ser adquiridas em http://www.dfi.ccet.ufms.br ou entrando em contato, via e-mail, com os autores.

\section{Referências}

BONFIM, A.K. (2000/2001) Influência do uso do programa Prometeus na alteração das concepções espontâneas de estudantes de Fúsica Básica. Projeto de Iniciação Científica.

BONFIM, A.K.; GOBARA, S.T. (2001) Uso do programa Prometeus nas alterações de concepções espontâneas em mecânica. Trabalho apresentado no XIV Simpósio Nacional de Ensino de Física, Natal, 02 a 06 de julho de 2001.

CAMPBELL, D.T.; STANLEY, J.C. (1979) Delineamentos experimentais e quase-experimentais de pesquisa. (São Paulo: EPU/EDUSP).

DRIVER, R.; ECKISON, G. (1983) Theories in action : Some theoretical and empirical issues in the study of students' conceptual framework in science. Studies in Science Education, 10, pp. 37-60.

GILBERT J. K.; ZYLBERZTAJN A. (1985) A conceptual framework for science education: the case study of force and movement, European Journal of Science Education, 7(2), pp. 107-120.

GOBARA, S.T.; ROSA, P.R.S.; PIUBELI, U.G. (2000) Análise da influência do uso de microcomputadores nas alterações das concepções espontâneas em nivel universitário básico. Trabalho apresentado na VII Conferência Interamericana sobre Educação em Física, Porto Alegre (Canela), 03 a 07 de julho de 2000.

GUIMARÃES, L. A. M.(1987) Concepções prévias $x$ concepções oficiais na física do segundo grau. Dissertação de Mestrado. Niterói, Universidade Federal Fluminense. 174 p.

OGBORN J. (1985) Understanding students understanding: an example from dynamics. European Journal of Science Education, 7(2), pp. 141-150.

PEDUZZI, O.Q.; PEDUZZI, S. (1985b) Força e movimento de projéteis. Cad. Cat. De Ensino de Física $\mathbf{2}(3)$.

PEDUZZI, O.Q.; PEDUZZI, S. (1985a) O conceito intuitivo de força no movimento e as duas primeiras leis de Newton. Cad. Cat. De Ensino de Física 2(1).

PIAGET, J., INHELDER, D. O desenvolvimento das quantidades físicas na criança. Rio de Janeiro, Zahar Editores, 1971. 
PIAGET, J. Vida e obra. In: A epistemologia genética; Sabedoria e ilusões da Filosofia; Problemas de Psicologia Genética. São Paulo, Abril Cultural, 1978. (Os Pensadores).

PIAGET, J. A equilibração das estruturas cognitivas Problema central do desenvolvimento. Trad. Marion Merlone dos Santos Penna. Zahar Editores, Rio de Janeiro, 1975. Ciências da Educação.

POSNER, G.J.; STRIKE, K. A.; HEWSON, P.W.; GERTZOG, W.A (1982) Accommodation of a scientific conception: Toward a theory of conceptual change. Science Education, 66(2), pp. 211-227.

ROSA, P.R.S. (1995) O uso de computadores no ensino de Física. Parte I: potencialidades e uso real. Revista Brasileira de Ensino de Física, 17(2), pp. 182-195.
ROSA, P.R.S.; PIUBÉLI, U.; GOBARA, S.T.; SILVA, N.O.; FARIA, G. Um software para a análise da influência do uso de microcomputadores nas alterações das concepções espontâneas em Física. Memorial Descritivo apresentado à comissãa de avaliação do Concurso Nacional de Software - Categoria Educacional, 1997.

SILVEIRA, F.L.; MOREIRA, M.A.; AXT, R. Validação de um teste para detectar se o aluno possui a concepção newtoniana sobre força e movimento. Ciência e Cultura, 38(12), 1986.

VIENNOT, L. (1979) Spontaneous reasoning in elementary dynamics. European Journal of Science Education, 2(1), pp. 205-221. 